\title{
Effects of aerobic and strength-based training on metabolic health indicators in older adults
}

\author{
Raul A Martins*1, Manuel T Veríssimo ${ }^{+1}$, Manuel J Coelho e Silva ${ }^{+1}$, Sean P Cumming ${ }^{+2}$ and Ana M Teixeira ${ }^{+1}$
}

\begin{abstract}
Background: The weakening of the cardiovascular system associated with aging could be countered by increasing levels of physical activity and functional fitness. However, inconsistent findings have been found, and the variety of characteristics of exercise used in previous studies may partly explain that inconsistent results.
\end{abstract}

Objective: To investigate the training effect of sixteen weeks of moderate intensity, progressive aerobic and strengthbased training on metabolic health of older women and men.

Methods: Sixty three sedentary individuals (mean (SD) age 76 (8) years) were randomly assigned to control $(n=31)$ or exercising $(n=32)$ groups. The training group was separated to aerobic $(n=18)$ or strength-based $(n=14)$. Training took place three times a week. Subjects agreed not to change their diet or lifestyle over the experimental period.

Results: Exercising group attained after treatment significant differences on body weight, waist circumference, body mass index, diastolic blood pressure, triglycerides, total cholesterol, HDL-cholesterol, LDL-cholesterol, total cholesterol/ HDL-cholesterol relationship, high sensitivity C-reactive protein, and 6-minute walk distance. The control group only had significant differences on waist circumference.

Conclusion: The training programs produced significant benefits on metabolic health indicators of sedentary older women and men.

\section{Background}

Age is associated with increases in body weight, body fat, abdominal fat $[1,2]$, and deterioration of the lipid profile $[3,4]$. Time spent engaging in sedentary activities also increases with age $[5,6]$ and is associated with obesity, atherosclerosis, and cardiovascular disease [7,8]. Conversely, regular involvement in moderate to vigorous bouts of physically active is documented as beneficial to cardiovascular health [9]. Accordingly, the weakening of the cardiovascular system associated with aging could be countered by increasing levels of physical activity and functional fitness $[10,11]$.

Aerobic-based training has been proposed as an effective mechanism for improving cardiovascular protection, with training resulting in reductions of $2 \%$ on total cholesterol (TC), $2 \%$ on low density lipoprotein cholesterol (LDL-C) and 9\% on triglycerides (TG), and increases of

\footnotetext{
* Correspondence: raulmartins@fcdef.uc.pt

1 Faculty of Sport Sciences and Physical Education, University of Coimbra,

Coimbra, Portugal

+ Contributed equally

Full list of author information is available at the end of the article
}

$3 \%$ on high density lipoprotein cholesterol (HDL-C) in men 18 years of age and older [12]. Research has also found positive training related adaptations on TC, TG, LDL-C and HDL-C [13], or only on LDL-C and TC/HDL$C$, without changes on TC, HDL-C and TG [14]. However, the variety of characteristics (frequency, intensity, time, and type) of exercise used in previous studies may partly explain inconsistent findings of different modes of aerobic exercise causing unchanged TC, HDL-C or LDL$C[15,16]$. Inconsistent results also exist in strength-based training programs with some failing to achieve changes in blood lipid profile in postmenopausal women $[17,18]$ or in adult men [16], while others have reported benefits [19]. Additionally, some studies focusing on the effects of the gender in the lipid profile have found significant differences, with women having higher HDL-C, decreased LDL-C, and decreased TG comparing with men [20]. High-sensitivy C-reactive protein (hs-CRP) is known to be a sensitive marker of inflammation and has also been related to increased risk of vascular disease [21,22]. Accordingly, factors that may interfere with hs-CRP lev- 
els, such as physical activity, require further investigation in populations that are at increased cardiovascular risk.

Considering the observed deterioration of the cardiovascular system and the metabolic profile that tends to accompany aging, it is important to know the potential benefits derived from the exercise. Although the effects of aerobic versus resistance training on cardiovascular risk factors have been compared [16,23], there is a need to further investigate the effects of the aerobic-based exercise versus strength-based exercise on body weight (BW), body mass index (BMI), waist circumference (WC), lipids, blood pressure, hs-CRP, and walking distance in older women and men. Accordingly, in the current study we hypothesized that moderate intensity, progressive aerobic-based and strength-based training would improve metabolic health of older women and men.

\section{Results}

At baseline evaluation (before treatment), no significant differences were observed between the exercising and control groups for any of the studied variables. Similarly there were no differences in the variables of interest across gender. At 16-week evaluation (after treatment), in the exercising group, no differences were observed between aerobic and strength-based training or between genders for any variable.

As shown in table 1, the exercising group attained after treatment significant differences on BW $(-1 \%)$, WC $(-3 \%)$, BMI (-1\%), diastolic blood pressure (DBP) (-4\%), TG (-

\section{Table 1: Exercise group}

\begin{tabular}{lcc}
\hline & Before & After \\
\hline Body weight [kg] & $73.1(11.0)$ & $72.3(10.7)^{*}$ \\
Waist circumference [cm] & $93.9(10.1)$ & $90.5(10.0)^{* *}$ \\
Body mass index [kg.m-2] & $30.6(5.0)$ & $30.3(4.9)^{*}$ \\
Blood pressure [mm Hg] & & \\
$\quad$ Systolic & $149.1(20.7)$ & $149.8(19.2)$ \\
$\quad$ Diastolic & $76.6(9.5)$ & $74.2(9.3)^{*}$ \\
Triglycerides [mmol.L-1] & $1.35(0.58)$ & $1.20(0.54)^{*}$ \\
Total cholesterol [mmol.L-1] & $5.64(0.86)$ & $5.29(1.03)^{*}$ \\
HDL-cholesterol [mmol.L-1] & $1.31(0.25)$ & $1.37(0.32)^{*}$ \\
LDL-cholesterol [mmol.L-1] & $2.36(0.77)$ & $2.05(0.86)^{* *}$ \\
Total Cholesterol/HDL-cholesterol & $4.40(0.92)$ & $4.02(0.81)^{* *}$ \\
hs-CRP [mg.L-1] & $5.41(3.94)$ & $3.99(1.97)^{*}$ \\
6-minute walk distance [m] & $387.0(75.9)$ & $437.2(82.5)^{* *}$ \\
\hline
\end{tabular}

Values are mean (SD).

${ }^{*} \mathrm{p}<0.05,{ }^{* *} \mathrm{p}<0.01$ compared with before.

HDL, high-density lipoprotein; LDL, low-density lipoprotein; hs-

$\mathrm{CRP}$, high-sensitivity C-reactive protein.
11\%), TC (-6\%), HDL-C (5\%), LDL-C (-13\%), TC/HDL-C relationship (-9\%), hs-CRP $(-26 \%)$, and 6-minute walk distance (13\%). The control group (table 2 ) only had significant differences on waist circumference $(-2 \%)$.

At baseline, BMI correlated with $\mathrm{TC}(\mathrm{r}=0.35, \mathrm{p}=$ 0.007), TG ( $\mathrm{r}=0.38, \mathrm{p}=0.004)$, and hs-CRP $(\mathrm{r}=0.46, \mathrm{p}=$ 0.001). WC correlated with TC $(\mathrm{r}=0.30, \mathrm{p}=0.022)$, TG $(\mathrm{r}$ $=0.35, \mathrm{p}=0.010)$, hs-CRP $(\mathrm{r}=0.38, \mathrm{p}=0.010)$, and TC/ HDL-C $(r=0.38, p=0.005)$. Finally, BW also correlated with TC $(\mathrm{r}=0.33, \mathrm{p}=0.011)$, TG $(\mathrm{r}=0.27, \mathrm{p}=0.044)$, hsCRP $(\mathrm{r}=0.40, \mathrm{p}=0.006)$, and TC/HDL-C $(\mathrm{r}=0.33, \mathrm{p}=$ 0.016).

\section{Discussion}

The main finding of this study is that both exercise programs (i.e., aerobic and strength-based) resulted in positive changes in important cardiovascular risk factors, namely TC, TG, LDL-C, HDL-C, TC/HDL-C, hs-CRP, $\mathrm{DBP}, \mathrm{BMI}, \mathrm{WC}$, and $\mathrm{BW}$, in a previously sedentary group of older women and men. Moreover, cardiorespiratory fitness also improves as result of the increase on the 6minute walk distance. Dietary composition is a potentially confounding factor and is known to influence lipoprotein concentrations. To minimize any confounding effects associated with variation in diet, all participants were fed a similar diet during the 16 weeks of the investigation. Both programs were successfully in that they both resulted in $13 \%$ gains on 6 -min walk distance. This observation suggests that aerobic and strength based exercise programs may result in improved cardiovascular functionality in older participants, potentially countering the documented age-related decline in peak oxygen uptake.

Following studies examining the effects of endurance and strength training on cardiovascular health have generally found either positive changes in lipid profile or no changes at all. More favorable changes in response to training occur usually in those with more pronounced dyslipidemia at baseline [24], and have been pointed as dependent on loss of body fat [25]. Our baseline values were normal for TG and HDL-C, optimal for LDL-C, and desirable (control group) and borderline high (exercising group) for TC, according to the guidelines [26]. Also, in the current study, at baseline in the total participant group, BMI, WC and BW correlated positively with TC, TG and hs-CRP. Moreover, WC and BW correlated with TC/HDL-C.

Our finding that TC, LDL-C, TG, and TC/HDL-C diminish with exercise is consistent with previous research [12,13], even those programs that have not attained resulted in gains after strength training in postmenopausal women [17] and in adult men [16]. To explain why some programs have not resulted in gains, some researchers have pointed a dose-response relationship between serum lipid levels (TC, TG, HDL-C, and 
TC/HDL-C) and levels of physical activity (intensity and duration) in adult women and men [6]. Accordingly, Cox and colleagues [27] have demonstrated lower TC and LDL-C after 6 months of higher-, but not lower-, intensity exercise in middle and older sedentary women. However, Sillanpaa and colleagues [16] failed to attain changes on TC, TG and LDL-C after 21-week of high-intensity endurance and heavy resistance strength training in healthy 40-65-year-old men. Independent of the mechanism underlying lipid changes, a reduction of $1 \%$ on TC has been shown to reduce the risk for coronary artery disease by $2 \%$ [28], which implies that our exercising participants have reduced about $12 \%$ their risk. Moreover, a $1 \%$ reduction in LDL-C reduces the risk of major coronary events by approximately $2 \%$ [29], which means that we have about a $26 \%$ gain.

Our finding that HDL-C increases with exercise is consistent with previous results $[12,13,19]$. However, not all studies have found gains in HDL-C following aerobicbased [14-16] or strength-based programs [16-18]. This absence of gains have been justified with the higher initial levels of HDL-C $[25,30]$, with the lower exercise intensity [31], with the good initial body composition [12], and with the lack of control of the time of blood sampling [32]. Seasonal fluctuations [33] and changes in dietary fat intake or leisure time physical activity may also influence the changes in the lipid profile [34,35]. Our baseline $\mathrm{HDL}-\mathrm{C}$ values were within normal range, and both exercising programs seem to have had enough intensity to promote gains on HDL-C, accompanied by reduction on BW, BMI, and WC. Also, a gap of at least 48 hours occurs between the last training session and the sampling. As a decrease of $1 \%$ on HDL-C has been associated with a 2 $3 \%$ increase in the risk for coronary heart disease (CHD) [36], and assuming that the reverse is true, the $5 \%$ increase observed in our both programs should decrease CHD by $10-15 \%$.

Recent data have shown decreases on resting blood pressure after prolonged endurance training of 1.9/1.6 (SBP/DBP) $\mathrm{mmHg}$ [37], and after strength training of about $3 \mathrm{mmHg}$ in both SBP and DBP [38,39]. This positive effects caused by the physical training have been more pronounced among hypertensive participants [39]. Participants in this study had normal DBP $(<80 \mathrm{~mm} \mathrm{Hg})$ and high SBP (140-159 $\mathrm{mm} \mathrm{Hg}$ ) at baseline. Interestingly, after the training only DBP have reduced $3 \mathrm{~mm} \mathrm{Hg}$ that may have clinical and biological relevance in the risk of heart disease.

In this study, aerobic and strength-based training have reduced $26 \%$ inflammation as measured by hs-CRP concentrations. Previous findings on the effect of strength and endurance training on hs-CRP levels have been inconsistent, with some studies showing benefits $[40,41]$ and others showing no effect at all $[42,43]$. The mecha- nisms underlying an exercise training-induced reduction in serum hs-CRP concentrations remain unknown. However, the lack of effects of exercise on hs-CRP has been explained by the few concomitant metabolic risk factors of the participants [16], and by a lack of changes in anthropometric variables (e.g., body weight, waist circumference) [43]. In fact, our participants at baseline have been sedentary, obese - particularly the exercising group (mean (SD) BMI $30.6(5.0) \mathrm{kg} / \mathrm{m}^{2}$ ), and hypertensive (mean (SD) SBP 148 (20) $\mathrm{mmHg}$ ). Moreover, the changes on BMI, WC and BW could help to justify the changes on hs-CRP. Additionally, the gains on muscular function as result of the increases on 6-minute walk distance would also influence the hs-CRP.

In conclusion, the training programs used in this study produced significant benefits on 6-minute walk distance, DBP, BW, WC, BMI, TG, TC, HDL-C, LDL-C, TC/HDL$\mathrm{C}$, and hs-CRP. Accordingly, the results of the current study suggest that moderate intensity aerobic-based and strength-based programs, with 16 weeks of duration, are enough to positively influence the metabolic health indicators of sedentary older women and men.

\section{Methods \\ Participants}

Sixty three sedentary individuals (65-95 years old) volunteered (mean (SD) age 76 (8) years) to participate in this study (38 women, 25 men). Participants were informed about any potential risks and/or discomforts associated with participation in the study and were required to provide their written informed consent before being included in the study. Participants who fulfilled the inclusion criteria and passed the baseline physical examination were randomized into two training groups and one control group. All the participants were from the same institution (St. House of Charity) and were provided with similar diets, in terms of caloric intake and nutrients, controlled by a nutritionist. Participants who were taking medications including aspirin and statins maintained unaltered posologies during the study. All the participants in the training groups performed the training as planned. The work was a part of a larger project, and the data have been partially reported earlier with a smaller number of subjects [44]. The study conforms to the laws of the country in which took place, and was approved by an ethical review board at University of Coimbra.

\section{Exclusion criteria}

Participants with impaired glucose tolerance and diabetes were excluded. All physical or psychological diseases that may have precluded ability to perform the requested training exercises and testing, and medications know to influence physical performance or interpretation of the findings were also considered exclusion criteria. 
Table 2: Control group

\begin{tabular}{lcc}
\hline & Before & After \\
\hline Body weight [kg] & $70.9(12.3)$ & $70.4(12.7)$ \\
Waist circumference [cm] & $93.3(9.9)$ & $90.9(10.2)^{* *}$ \\
Body mass index [kg.m $\left.{ }^{-2}\right]$ & $29.0(4.4)$ & $28.8(4.7)$ \\
Blood pressure [mm Hg] & & \\
$\quad$ Systolic & $146.1(20.2)$ & $142.5(23.6)$ \\
$\quad$ Diastolic & $76.2(8.6)$ & $75.4(13.1)$ \\
Triglycerides [mmol.L-1] & $1.10(0.35)$ & $1.15(0.35)$ \\
Total cholesterol [mmol.L-1] & $5.14(0.94)$ & $5.27(1.02)$ \\
HDL-cholesterol [mmol.L-1] & $1.33(0.28)$ & $1.32(0.29)$ \\
LDL-cholesterol [mmol.L-1] & $2.39(0.86)$ & $2.27(0.61)$ \\
Total Cholesterol/HDL-cholesterol & $3.99(0.98)$ & $4.07(0.83)$ \\
hs-CRP [mg.L-1] & $5.5(3.5)$ & $5.1(2.3)$ \\
6-minute walk distance [m] & $341.9(125.9)$ & $342.9(169.8)$ \\
\hline
\end{tabular}

Values are mean (SD).

${ }^{*} \mathrm{p}<0.05,{ }^{* *} \mathrm{p}<0.01$ compared with before.

$\mathrm{HDL}$, high-density lipoprotein; LDL, low-density lipoprotein; hs-CRP, high-sensitivity C-reactive protein.

\section{Aerobic-based training}

The training was supervised by an Exercise Physiologist, and the frequency was kept three times per week for 16 weeks, with 45 minutes per session. The intensity of the main part of the session started with work heart rate (HR) of $40-50 \% \mathrm{HR}_{\text {reserve }}\left(1-4^{\text {th }}\right.$ week), increasing progressively to $51-60 \% \mathrm{HR}_{\text {reserve }}\left(5-8^{\text {th }}\right.$ week $), 61-70 \% \mathrm{HR}_{\text {reserve }}\left(9-12^{\text {th }}\right.$ week), and to $71-85 \% \mathrm{HR}_{\text {reserve }}\left(13-16^{\text {th }}\right.$ week).

\section{Strength-based training}

After an adequate warm up, the participants completed resistance exercise for three days a week for 16 weeks. They performed eight exercises with elastic bands for the major muscular groups respecting the following progression: 1 set of 8 repetitions (1-2nd week), 1 set of 12 reps (3$4^{\text {th }}$ weeks), 2 sets of 8 reps (5- $6^{\text {th }}$ weeks), 2 sets of 10 reps (7-8 $8^{\text {th }}$ weeks), 2 sets of 12 reps (9-10 th week), 2 sets of 15 reps (11-12 th weeks), 3 sets of 12 reps (13-14, ${ }^{\text {th }}$ weeks), and 3 sets of 15 reps $\left(15-16^{\text {th }}\right.$ weeks). An interval period of at least three minutes was assured between sets of the same exercise.

\section{Anthropometry}

Anthropometric assessment was carried out in a separate room, taking care to ensure the participants privacy. Body weight was determined using a portable scale (Seca ${ }^{\oplus}$, model 770, Germany) with a precision of 0.1 kilogram. Waist circumference was measured using a retractable glass fiber tape measure (Hoechstmass-Rollfix ${ }^{\oplus}$,
Germany) with a precision of 0.1 centimeters. Stature was determined using a portable stadiometer (Seca Bodymeter $^{\oplus}$, model 208, Germany) with a precision of 0.1 centimetres.

\section{Functional fitness}

The 6-minute walk test was applied before and after exercising programs and assessed the aerobic endurance measuring the distance around a 50 metres course covered in 6-minutes [45].

\section{Blood pressure}

Resting blood pressure was measured by the auscultation method using sphygmomanometer (Aneroid Sphygmomanometer-HICO HM $1001^{\circ}$, Germany) and stethoscope (Nurse Type Professional Stethoscope-HICO HM-3005 ${ }^{\circledR}$, Germany). Participants were in sitting position respecting the procedures for assessment of resting blood pressure presented by the ACSM [46].

\section{Blood sampling}

Venous blood samples were collected into EDTA containing tubes, in the morning between 8:00 am and 9:30 am by two specialized nurses, after 12 hours fasting, and after a minimum of 48 hours since the last physical exercise intervention. Participants were in a seated position and rested for five minutes. Determinations of the lipids and hs-CRP used a bench top clinical chemistry analyzer (RX imola, Randox Laboratories Ltd, UK). Determination of hs-CRP concentration was done by immunoturbidimetry (High sensitivity CRP kit, Randox Laboratories Ltd, UK). All the cholesterol determination tests used were direct enzymatic clearance tests from the Randox Laboratories. TC was determined using a Trider-based (CHOD-PAP) colorimetric end-point assay $(\mathrm{CH} 3810$, Randox Laboratories Ltd, UK). HDL-C was determined using a direct two-point kinetic assay kit $(\mathrm{CH} 2652$, Randox Laboratories Ltd, UK). LDL-C determination was done using a direct two-point kinetic assay kit (CH 9702, Randox Laboratories Ltd, UK). TG were determined using a Trinderbased (GPO-PAP) colorimetric end point assay (TR 3823, Randox Laboratories Ltd, UK). All the methods were controlled and validated using external controls from INSA and RIQAS.

\section{Statistical analysis}

Differences between groups (exercising and control), between genders (females and males), and between exercising subgroups (aerobic and strength-based) were analyzed using a univariate analysis of variance. Differences between evaluations (before and after) were analyzed with a univariate analysis of variance for repeated measures. $\mathrm{F}$ and $\mathrm{p}$ values from the Pillai test were calculated for within participant's comparisons. Bonferroni's tests 
were used for multiple comparisons. Values are expressed as mean and standard deviation (SD), and statistical significance was accepted at the $\mathrm{p}<0.05$ level.

\section{Competing interests}

The authors declare that they have no competing interests.

\section{Authors' contributions}

RAM participated in the design of the study, participated in the exercise protocols, performed the statistical analysis and drafted the manuscript. MTV, MJCS and AMT participated in the design of the study and in its coordination and helped to draft the manuscript. SPC participated in the draft of the manuscript and revising it critically for important intellectual content. All authors read and approved the final manuscript.

\section{Acknowledgements}

This work was supported by the Portuguese Foundation for Science and Technology (FCT) and the Portuguese Institute of Sport (IDP).

\section{Author Details}

'Faculty of Sport Sciences and Physical Education, University of Coimbra, Coimbra, Portugal and 25 chool of Health, University of Bath, Bath, UK

Received: 23 June 2010 Accepted: 22 July 2010

Published: 22 July 2010

\section{References}

1. Kohrt WM, Obert KA, Holloszy JO: Exercise training improves fat distribution patterns in 60- to 70-year old men and women. $J$ Gerontol 1992, 47:M99-M105.

2. Ryan AS, Nicklas BJ: Age-related changes in fat deposition in midthigh muscle in women: relationships with metabolic cardiovascular disease risk factors. Int J Obes Relat Metab Disord 1999, 23:126-132.

3. Short KR, Vittone JL, Bigelow ML, Proctor DN, Rizza RA, Coenen-Schimke $J M$, Nair KS: Impact of aerobic training on age-related changes in insulin sensitivity and muscle oxidative capacity. Diabetes 2003 , 52:1888-1896

4. Harris MI, Flegal KM, Cowie CC, Eberhardt MS, Goldstein DE, Little RR, Wiedmeyer HM, Byrd-Holt DD: Prevalence of diabetes, impaired fasting glucose, and impaired glucose tolerance in U.S. adults. The Third National Health and Nutrition Examination Survey, 1988-1994. Diabetes Care 1998, 21:518-524.

5. Schoenborn CA, Adams PF, Barnes PM, Vickerie JL, Schiller JS: Health behaviors of adults: United States, 1999-2001. Vial Health Stat 2004, 219:1-79.

6. Thune I, Njolstad I, Lochen ML, Forde OH: Physical activity improves the metabolic risk profiles in men and women. Arch Intern Med 1998, 158:1633-1640.

7. Wilson PW, D'Agostino RB, Sullivan L, Parise H, Kannel WB: Overweight and obesity as determinants of cardiovascular risk: the Framingham experience. Arch Intern Med 2002, 162:1867-1872.

8. Calle EE, Thun MJ, Petrelli JM, Rodriguez C, Heath CW Jr: Body-mass index and mortality in a prospective cohort of U.S. adults. N Engl J Med 1999, 341:1097-1105.

9. U.S Department of Health and Human Services: Physical Activity and Health: A Report of the Surgeon General Atlanta, GA: U.S. Department of Health and Human Services, Centers for Disease Control and Prevention, National Center for Chronic Disease Prevention and Health Promotion 1996.

10. Black MA, Green DJ, Cable NT: Exercise prevents age-related decline in nitric-oxide-mediated vasodilator function in cutaneous microvessels. J Physiol 2008, 586:3511-3524.

11. Trott DW, Gunduz F, Laughlin MH, Woodman CR: Exercise training reverses age-related decrements in endothelium-dependent dilation in skeletal muscle feed arteries. J Appl Physiol 2009, 106:1925-1934.

12. Kelley GA, Kelley KS: Aerobic exercise and lipids and lipoproteins in men: a meta-analysis of randomized controlled trials. J Mens Health Gend 2006, 3:61-70.

13. Halverstadt A, Phares DA, Wilund KR, Goldberg AP, Hagberg JM: Endurance exercise training raises high-density lipoprotein cholesterol and lowers small low-density lipoprotein and very low-density lipoprotein independent of body fat phenotypes in older men and women. Metabolism 2007, 56:444-450.

14. Kelley GA, Kelley KS, Tran ZV: Walking lipids and lipoproteins: a metaanalysis of randomized controlled trials. Prev Med 2004, 38:651-661.

15. Cox KL, Burke V, Beilin LJ, Puddey IB: A comparison of the effects of swimming and walking on body weight, fat distribution, lipids, glucose, and insulin in older women - the Sedentary Women Exercise Adherence Trial 2. Metabolism 2010 [http://www.ncbi.nlm.nih.gov/ pubmed/20197194]. Published Online First

16. Sillanpaa E, Hakkinen A, Punnonen K, Häkkinen K, Laaksonen DE: Effects of strength and endurance training on metabolic risk factors in healthy 40-65-year-old men. Scand J Med Sci Sports 2009, 19:885-895.

17. Elliott KJ, Sale C, Cable NT: Effects of resistance training and detraining on muscle strength and blood lipid profiles in postmenopausal women. Br J Sports Med 2002, 36:340-345.

18. Marques E, Carvalho J, Soares JMC, Marques F, Mota J: Effects of resistance and multicomponent exercise on lipid profiles of older women. Maturitas 2009, 63:84-88.

19. Tucker $L A$, Silvester $L J$ : Strength training and hypercholesterolemia: an epidemiologic study of 8499 employed men. Am J Health Promot 1996, 11:35-41.

20. Garelnabi M, Veledar E, Abramson J, et al.: Physical Inactivity and Cardiovascular Risk: Baseline Observations from Men and Premenopausal Women. J Clin Lab Anal 2010, 24:100-105.

21. Koenig W, Sund M, Fröhlich M, Fischer HG, Löwel H, Döring A, Hutchinson WL, Pepys MB: C-Reactive protein, a sensitive marker of inflammation, predicts future risk of coronary heart disease in initially healthy middle-aged men: results from the MONICA (Monitoring Trends and Determinants in Cardiovascular Disease) Augsburg Cohort Study, 1984 to 1992. Circulation 1999, 99:237-242.

22. Ridker PM, Buring JE, Cook NR, Rifai N: C-reactive protein, the metabolic syndrome, and risk of incident cardiovascular events: an 8-year followup of 14719 initially healthy American women. Circulation 2003, 107:391-397.

23. Poehlman ET, Dvorak RV, Denino WF, Brochu M, Ades PA: Effects of resistance training and endurance training on insulin sensitivity in nonobese, young women: a controlled randomized trial. J Clin Endocrinol Metab 2000, 85:2463-2568.

24. Laaksonen DE, Atalay M, Niskanen LK, Mustonen J, Sen CK, Lakka TA, Uusitupa MI: Aerobic exercise and the lipid profile in type 1 diabetic men: a randomized controlled trial. Med Sci Sports Exerc 2000, 32:1541-1548.

25. Leon AS, Sanchez OA: Response of blood lipids to exercise training alone or combined with dietary intervention. Med Sci Sports Exerc 2001, 33:S502-S515. discussion S528-S529

26. National Cholesterol Education Program: Third Report of the National Cholesterol Education Program (NCEP) Expert Panel on Detection, Evaluation, and Treatment of High Blood Cholesterol in Adults (Adult Treatment Panel III) Volume 02. Washington, DC: NIH Publication; 2002:5215.

27. Cox KL, Burke V, Morton AR, Gillam HF, Beilin L, Puddey IB: Long-term effects of exercise on blood pressure and lipids in healthy women aged 40-65 years: the Sedentary Women Exercise Adherence Trial (SWEAT). J Hypertens 2001, 19:1733-1743.

28. Consensus Development Panel: Consensus conference. Lowering blood cholesterol to prevent heart disease. JAMA 1985, 253:2080-2086.

29. Pedersen TR, Olsson AG, Faergeman O, Kjekshus J, Wedel H, Berg K, Wilhelmsen L, Haghfelt T, Thorgeirsson G, Pyörälä K, Miettinen T, Christophersen B, Tobert JA, Musliner TA, Cook TJ: Lipoprotein changes and reduction in the incidence of major coronary heart disease events in the Scandinavian Simvastatin Survival Study (4S). Circulation 1998, 97:1453-1460.

30. Tully MA, Cupples ME, Chan WS, MCGlade K, Young IS: Brisk walking, fitness and cardiovascular risk: a randomized controlled trial in primary care. Prev Med 2005, 41:622-628.

31. Stensel DJ, Brookewavell K, Hardman AE, Jones PRM Norgan NG: The influence of a 1-year program of brisk walking on endurance fitness and body composition in previously sedentary men aged $42-59$ years. Eur J Appl Physiol Occup Physiol 1994, 68:531-537.

32. Boreham CAG, Kennedy RA, Murphy MH, Tully M, Wallace WFM, Young I: Training effects of short bouts of stair climbing on cardiorespiratory fitness, blood lipids, and homocysteine in sedentary young women. $\mathrm{Br}$ J Sports Med 2005, 39:590-593. 
33. Manttari M, Javela K, Koskinen P, Pikkarainen J, Manninen V, Huttunen JK Frick MH: Seasonal variation in high density lipoprotein cholesterol. Atherosclerosis 1993, 100:257-265.

34. Matthews CE, Freedson PS, Hebert JR, Stanek EJ III, Merriam PA, Rosal MC, Ebbeling CB, Ockene IS: Seasonal variation in household, occupational, and leisure time physical activity: longitudinal analyses from the seasonal variation of blood cholesterol study. Am J Epidemiol 2001, 153:172-183.

35. Ockene IS, Chiriboga DE, Stanek EJ III, Harmatz MG, Nicolosi R, Saperia G, Well AD, Freedson P, Merriam PA, Reed G, Ma Y, Matthews CE, Hebert JR: Seasonal variation in serum cholesterol levels: treatment implications and possible mechanisms. Arch Intern Med 2004, 164:863-870.

36. Gordon DJ, Probstfield JL, Garrison RJ, Neaton JD, Castelli WP, Knoke JD, Jacobs DR Jr, Bangdiwala S, Tyroler HA: High density lipoprotein cholesterol and cardiovascular disease: Four prospective American studies. Circulation 1989, 79:8-15.

37. Kelley GA, Kelley KA, Tran ZV: Aerobic exercise and resting blood pressure: a meta-analytic review of randomized, controlled trials. Prev Cardiol 2001, 4:73-80.

38. Kelley GA, Kelley KS: Progressive resistance exercise and resting blood pressure: a meta-analysis of randomized controlled trials. Hypertension 2000, 35:838-843.

39. Cornelissen VA, Fagard RH: Effect of resistance training on resting blood pressure: a meta-analysis of randomized controlled trials. J Hypertens 2005, 23:251-259.

40. You T, Berman DM, Ryan AS, Nicklas BJ: Effects of hypocaloric diet and exercise training on inflammation and adipocyte lipolysis in obese postmenopausal women. J Clin Endocrinol Metab 2004, 89:1739-1746.

41. Kim ES, Im JA, Kim KC, Park JH, Suh SH, Kang ES, Kim SH, Jekal Y, Lee CW, Yoon YJ, Lee HC, Jeon JY: Improved insulin sensitivity and adiponectin level after exercise training in obese Korean youth. Obesity 2007, 15:3023-3030

42. Marcell TJ, McAuley KA, Traustadottir T, Reaven PD: Exercise training is not associated with improved levels of Creactive protein or adiponectin. Metabolism 2005, 54:533-541.

43. Zoppini G, Targher G, Zamboni C, Venturi C, Cacciatori V, Moghetti P, Muggeo M: Effects of moderate-intensity exercise training on plasma biomarkers of inflammation and endothelial dysfunction in older patients with type 2 diabetes. Nutr Metab Cardiovasc Dis 2006, 16:543-549.

44. Martins RA, Neves AP, Coelho-Silva MJ, Veríssimo MT, Teixeira AM: Highsensitivity C-reactive protein, body fat and physical exercise in older people. Eur J Appl Physio/ 2010 [http://www.ncbi.nlm.nih.gov/pubmed/ 20437055]. Published Online First

45. Rikli RE, Jones CJ: Development and validation of a functional fitness test for community-residing older adults. J Aging Phys Activ 1999, 7:129-161.

46. American College of Sports Medicine: ACSM's Guidelines for Exercise Testing and Prescription 7th edition. Philadelphia: Lippincott Williams \& Wilkins; 2006.

doi: $10.1186 / 1476-511 X-9-76$

Cite this article as: Martins et al., Effects of aerobic and strength-based training on metabolic health indicators in older adults Lipids in Health and Disease 2010, 9:76

Submit your next manuscript to BioMed Centra and take full advantage of:

- Convenient online submission

- Thorough peer review

- No space constraints or color figure charges

- Immediate publication on acceptance

- Inclusion in PubMed, CAS, Scopus and Google Scholar

- Research which is freely available for redistribution

Submit your manuscript at www.biomedcentral.com/submit
C Biomed Central 